\title{
0 peso do baço em chagásicos crônicos
}

\author{
Weight of the spleen in chronic chagasic patients
}

\author{
Sanívia Aparecida de Lima Pereira, Beatriz Soares Corrêa, G isela Paludeto \\ Minicucci, G lauce Marlei Aires Lopes, Eumênia Costa da Cunha Castro, \\ Marlene Antônia dos Reis e Vicente de Paula Antunes Teixeira
}

\begin{abstract}
Resumo $O$ baço pode aumentar de tamanho nas inflamacões com repercussões sistêmicas e na congestão venosa crônica, denominando-se respectivamente, hiperplasia reacional e esplenomegalia congestiva. Sendo a doença de Chagas uma doença infecciosa com repercussões hemodinâmicas, possivelmente o baço responda năo só ao envolvimento cardíaco, como também ao processo inflamatório. O objetivo deste trabalho é avaliar comparativamente o peso do baco em chagásicos ou não-chagásicos, com ou sem insuficiência cardíaca congestiva (ICC). Em estudo retrospectivo foram coletados nos protocolos de necropsias de adultos, a idade, o sexo, a cor e o peso do baço. Os 88 casos selecionados foram divididos em quatro grupos: 1) chagásicos com ICC, 2) chagásicos sem ICC, 3) não-chagásicos com ICC e 4) não-chagásicos sem ICC. A idade média fol 44,9 $\pm 15,4$ anos, sendo $53,4 \%$ brancos e $70,5 \%$ do sexo masculino, não havendo diferença significante destas variáveis entre os grupos. O peso do baço nos grupos com ICC foi de 183,7 $\pm 85,9 \mathrm{~g}$ para os chagásicos e de 206,3 $\pm 101,0 \mathrm{~g}$ para os nấo-chagásicos. Nos grupos sem ICC o peso foi de 173,7 \pm $118,9 \mathrm{~g}$ para os chagásicos e de 117,2 \pm 52,0g para os não-chagásicos. O peso foi significantemente maior nos chagásicos sem ICC quando comparados aos não-chagásicos sem ICC. Estes resultados sugerem que o componente inflamatório na doença de Chagas desempenharia papel importante no aumento do peso do baço, associado às alterações hemodinâmicas decorrentes da ICC.
\end{abstract}

Palavras-chaves: Baço. Doença de Chagas. Peso do baço. Trypanosoma cruzi.

\begin{abstract}
During the course of systemic inflammatory reactions and chronic venous congestion, the documented phenomenon of increased spleen size is respectively called reactional hyperplasia and congestive splenomegaly. In Chagas' disease, the inflammatory process observed in the heart of chronically infected patients can result in heart failure and ultimately in congestive failure. In order to evaluate the spleen response to both inflammatory and cardiac processes, in this retrospective study we compare the weight of spleens from normal and chagasic patients, with or without congestive failure. Information about patient age, sex, race and spleen weight was collected from autopsy reports. Eighty-eight selected cases were divided into four groups: 1) chagasic patients with congestive failure, 2) chagasic patients without congestive failure, 3) non-chagasic patients with congestive failure, 4) non-chagasic patients without congestive failure. The average age was $44.9 \pm$ 15.4 years, $53.4 \%$ were Caucasians and $70.5 \%$ were males, and no significant difference in these parameters was observed between the four groups. The spleen weight for the groups presenting cong estive failure was $183.7 \pm 85.9 \mathrm{~g}$ for chagasic and $206.3 \pm 101.0 \mathrm{~g}$ for non-chagasic patients; for the groups without congestive failure the average spleen weight was $173.7 \pm 118.9 \mathrm{~g}$ for the chagasic and $117.2 \pm 52.0 \mathrm{~g}$ for non-chagasic patients. The spleen weight was significantly higher for the chagasic patients without congestive failure when compared to the non-chagasic group without congestive failure. These results suggest that the inflammatory component in Chagas' disease plays an important role in the increase of spleen weight together with hemodynamic alterations arising from congestive heart failure.
\end{abstract}

Key-words: Chagas' disease. Spleen. Trypanosoma cruzi. Spleen weight.

Disciplinas de Patologia Geral da Universidade de Uberaba e da Faculdade de Medicina do Triângulo Mineiro, Uberaba, MG.

Apoio financeiro: Fundação de Ensino e Pesquisa de Uberaba (FUNEPU), Fundação de Amparo à Pesquisa do Estado de Minas Gerais (FAPEMIG) e Conselho Nacional de Desenvolvimento Científico e Tecnológico (CNPq).

Endereço para correspondência: Prof. Vicente de Paula Antunes Teixeira. Disciplina de Patologia Geral/FMTM. R. Frei Paulino 30, 38025-180 Uberaba, MG. E-mail: vicpat@mednet.com.br

Recebido para publicação em 15/5/98. 
O baço em humanos adultos pesa cerca de $150 \mathrm{~g}$, tendo as funções de filtrar corpos estranhos da circulação e de participar da resposta imunitária através de linfócitos T e B10. Macroscopicamente, o baço pode ser dividido em uma porção denominada polpa vermelha, rica em eritrócitos, e outra denominada polpa branca onde se encontram nódulos de tecido linfóide. É na polpa vermelha que o sangue é filtrado, enquanto a polpa branca é responsável pela defesa imunológica12.

Como a maior unidade do sistema mononuclear fagocitário (SMF), o baço é envolvido em todas as inflamações sistêmicas, quando geralmente aumenta de tamanho, sendo nestes casos denominado baço ativado ${ }^{9}$ ou estado reacional hiperplásico10. A esplenomegalia do estado reacional hiperplásico é causada sobretudo pelas modificações dos cordões de Billroth, constituído pelo tecido linfóide, e dos seios, ocupados pelos elementos do sangue circulante. Nestes casos, não há inflamação do órgão, mas apenas exaltação adaptativa de suas funções normais, podendo ter uma forma aguda e outra crônica, sendo que nesta última o baço pode aumentar consideravelmente de volume10.

Igualmente, nos casos de congestão venosa persistente ou crônica, há aumento do baço denominado esplenomegalia congestiva 9 . A hiperemia passiva de origem cardíaca pode ocorrer na insuficiência cardíaca congestiva (ICC) de qualquer causa, mas especialmente nos defeitos valvares direitos e no cor pulmonale crônico. Nesses casos o baço se torna rígido, duro e com a cápsula tensa 10 .

Comparativamente, em ratos infectados pelo Schistosoma mansoni, também uma doença infecciosa como a doença de Chagas, verificouse uma elevação proporcional no número de neutrófilos, plasmócitos, macrófagos e eosinófilos no baço. Foi encontrado ainda, um retardo na evolução dos granulomas periovulares em ratos esplenectomizados, quando linfonodos ou outros órgãos linfóides secundários assumem o papel modulador5.

Por ser a doença de Chagas um processo patológico infeccioso, com repercussões hemodinâmicas, foi proposta a hipótese de uma possível modificação do peso do baço, respondendo não só ao envolvimento cardíaco, como também ao processo inflamatório crônico sistêmico. Assim, o objetivo deste trabalho foi avaliar comparativamente o peso do baço em indivíduos chagásicos crônicos ou nãochagásicos, com ou sem insuficiência cardíaca congestiva.

\section{MATERIAL E MÉTODOS}

Em um estudo retrospectivo, foram consultados 3993 protocolos de necropsias completas, realizadas no Hospital Escola da Faculdade de Medicina do Triângulo Mineiro, em Uberaba, MG. Nesse estudo, foram selecionadas as necropsias de adultos, sendo pareados quanto à cor, à idade e ao sexo. Nestes protocolos, foi coletado o peso do baço de cada indivíduo.

Os casos selecionados foram divididos em quatro grupos: 1. chagásicos com ICC; 2. chagásicos sem ICC; 3 . não-chagásicos com ICC; 4. não-chagásicos sem ICC.

Nesta classificação, baseada nos protocolos de necropsias, foram considerados chagásicos os indivíduos que apresentaram as reações de Machado-Guerreiro, imunofluorescência indireta e de hemaglutinação para $T$. cruzi positivas, realizadas no líquido pericárdico colhido à necropsia. Os critérios de inclusão para os grupos com ICC foram a presença de órgãos cardíacos e anasarca, além das alterações cardíacas características. Foram excluídos os casos de neoplasias, entre elas as leucemias e os linfomas, as inflamações sistêmicas agudas ou crônicas graves, tais como, endocardites, pneumonites e leptomeningites e quaisquer outras doenças que pudessem interferir no peso do baço por desenvolver hipertensão porta, observada por exemplo, nos casos de cirrose e esquistossomose hepáticas.

A análise estatística foi feita através dos testes $t$ de Student, e $U$ de Mann-Whitney. As diferenças observadas foram consideradas significantes quando a probabilidade de rejeição da hipótese de nulidade foi menor que 0,05 $(5 \%)$.

\section{RESULTADOS}

Foram selecionados 88 casos que preenchiam as condições pretendidas. A idade média foi $44,9 \pm 15,4$ anos, sendo $53,4 \%$ brancos e $70,5 \%$ do sexo masculino, não havendo diferença significante destas variáveis entre os grupos. A Tabela 1 mostra o peso do baço em indivíduos 
chagásicos ou não-chagásicos, com ou sem ICC. O peso do baço foi significantemente maior nos pacientes chagásicos sem ICC, quando comparados com os não-chagásicos sem ICC (Teste de Mann-Whitney entre chagásicos e não-chagásicos sem ICC, $U=4,397 ; p=0,036$ ).

Tabela 1 - Comparação do peso do baço em pacientes chagásicos crônicos ou não-chagásicos necropsiados, com ou sem insuficiência cardíaca congestiva (ICC).

\begin{tabular}{|c|c|c|c|}
\hline \multirow{3}{*}{ Pacientes } & \multicolumn{3}{|c|}{ Peso do baço (g) } \\
\hline & Com ICC $(n=43)$ & Sem ICC $(n=45)$ & Total $(n=88)$ \\
\hline & $(X \pm S)$ & $(X \pm S)$ & $(X \pm S)$ \\
\hline \multirow[t]{2}{*}{ Chagásicos } & $n=32$ & $n=20$ & $n=52$ \\
\hline & $183,7 \pm 85,9$ & $173,7 \pm 118,9^{*}$ & $179,9 \pm 98,8$ \\
\hline \multirow[t]{2}{*}{ Não-chagásicos } & $\mathrm{n}=11$ & $n=25$ & $n=36$ \\
\hline & $206,3 \pm 101,0$ & $117,2 \pm 52,0$ & $144,4 \pm 80,6$ \\
\hline Total & $189,5 \pm 89,3^{* *}$ & $142,3 \pm 91,6$ & $165,4 \pm 93,0$ \\
\hline
\end{tabular}

*Teste de Mann-Whitney entre chagásicos e não-chagásicos sem ICC, $U=4,397 ; \mathrm{p}=0,036$.

** Teste $t$ de Student entre pacientes com ICC e sem ICC, $t=2,446 ; p=0,016$.

\section{DISCUSSÃO}

No presente estudo, o peso do baço nos indivíduos sem ICC foi significativamente maior entre os chagásicos, quando comparados aos não-chagásicos. Na literatura não foi encontrada nenhuma referência à esplenomegalia na fase crônica da doença de Chagas. Entretanto, este aumento já foi observado na fase aguda da doença humana 1417.

Myers e cols 15 descreveram que o peso do baço adulto normal pode ser variável, com limites de normalidade incertos e não concordantes nos vários estudos de revisão. Estes autores, analisando 366 baços de vítimas de morte acidental, sem apresentarem qualquer doença prévia, observaram que o peso do baço foi maior em indivíduos jovens, brancos e do sexo masculino. Observaram ainda, que com relação ao peso normal, houve uma variação de 35 gramas em mulher negra para 280 gramas em homem branco, com idade inferior a 25 anos. Contudo, Scothorne ${ }^{19}$ não encontrou evidências de influência da idade com relação especificamente ao volume da polpa branca. Ainda assim, no presente trabalho, os indivíduos foram pareados quanto ao sexo, a idade e a cor.

$\mathrm{Na}$ fase aguda experimental da doença de Chagas, o aumento do baço tem sido explicado pela alta reatividade, comprovada pela hiperplasia dos centros germinativos 48 , proliferação de linfócitos 4 , produção de anticorpos 2 e expansão dos folículos linfóides6 8 . Por outro lado, Carvalho Filho e cols 7 , analisando 24 casos de necropsias de pacientes portadores da forma grave de estrongiloidíase, associada ou não a uma doença preexistente, encontraram diminuição do peso do baço, atrofia dos folículos linfóides com ausência de centros germinativos, presença de plasmócitos e neutrófilos, hiperplasia de células reticulares, grumos bacterianos, às vezes com formação de micro-abscessos.

O parasitismo esplênico observado na fase aguda experimental da doença de Chagas, às vezes é intenso 16. No entanto, a esplenectomia não modifica a parasitemia, tanto na fase aguda quanto na crônica. Demonstrou-se ainda que há participação do baço na produção de anticorpos na fase aguda, porém sem influenciar o curso da infecção13.

O aumento do peso do baço nos chagásicos crônicos que apresentam ICC, poderia ser conseqüente não apenas ao fator hemodinâmico, mas também um reflexo da resposta sistêmica à infecção chagásica. Esta resposta poderia ser explicada pela persistência do T. cruzi ou de seus antígenos no baço, como já foi comprovada em outros órgãos 131120 . Isto implicaria em um aumento da neoformação de tecido conjuntivo, no afluxo e na circulação leucocitária, que contribuiriam para o aumento do peso esplênico.

No presente estudo, os resultados sugerem que o componente inflamatório na doença de Chagas humana desempenharia papel importante no aumento do peso do baço, juntamente com as alterações hemodinâmicas decorrentes da ICC. É possível que após a esplenomegalia da fase aguda, o peso do baço diminua com o desenvolvimento da fase crônica, entretanto, sem voltar aos valores observados em controles. 
Talvez este aumento do peso esplênico possa refletir a modulação do sistema mononuclear fagocitário deste órgão na fase crônica da doença de Chagas.

\section{AGRADECIMENTOS}

Os autores agradecem a Maria Prado de Morais, Maria Helena Costa Batista, Aloísio Costa e Leônidas Venâncio da Cunha, pelos serviços técnicos prestados, e ao Dr. Giovanni Franchin pelas críticas e sugestões.

\section{REFERÊNCIAS BIBLIOGRÁFICAS}

1. Adad SJ, Andrade DC, Lopes ER, Chapadeiro E. Pathological anatomy of chagasic megaesophagus. Revista do Instituto de Medicina Tropical de São Paulo 33:443-450, 1991.

2. Alcântara Filho A, Krettli AU, Brenner Z. Role the spleen in the experimental infection by T. cruzi in mice. In: Anais da V Reunião Anual de Pesquisa Básica em Doença de Chagas, Caxambu, p. C-33, 1978.

3. Almeida HO, Teixeira VPA, Gobbi H, Rocha A, Brandão MC. Inflamação associada a células musculares cardíacas parasitadas pelo Trypanosoma cruzi, em chagásicos crônicos. Arquivo Brasileiro de Cardiologia 42:183-186, 1984.

4. Andrade ZA. A patologia da doença de Chagas no homem. Annales de La Societe Belge de Medecine Tropical 65:15-30, 1985.

5. Arruda SM, Santoro F, Sadigurshy M. Evaluation of spleen cell population and effect of splenectomy on granuloma modulation in BALB/c mice infected with Schistosoma mansoni. Memórias do Instituto Oswaldo Cruz 88: 97-102, 1993.

6. Camargo IJ, Araújo PM, Sakurada JK, Stach-Machado DR, Rangel HA. Trypanosoma cruzi: early resistance induced by culture-derived trypomastigotes. Experimental Parasitology 73:260-268, 1991.

7. Carvalho Filho E, Queiroz AC. Histopatologia do baço em portadores de estrongiloidíase grave. Revista Médica da Bahia 22:80-84, 1976.

8. Cordeiro SMS, Dahia ACG, Andrade ZA. Kinetics of Trypanosoma cruzi destruction in the mouse spleen. Revista da Sociedade Brasileira de Medicina Tropical 30:3-9, 1987.

9. Cotran RS, Kumar V, Robbins SL. Doenças dos leucócitos, linfonodos e baço. In: Cotran RS, Kumar V, Robbins SL (eds) Robbins Patologia Estrutural e Funcional. 5 $5^{\underline{a}}$ edição. Editora Guanabara-Koogan, Rio de Janeiro, p.557-597, 1996.

10. Franco M, Schmitt FC, Bacchi MM, Marigo C, Paes RP. Sistema hemolinfopoiético. In: Brasileiro Filho G, Pittella JEH, Pereira FEL, Bambirra EA, Barbosa AJA (eds) Bogliolo Patologia. 5ª edição. Editora Guanabara-Koogan, Rio de Janeiro, p.665-722, 1994.
11. Jones EM, Colley DG, Tostes S, Lopes ER, VnencakJones CL, McCurley TL. Amplification of a Trypanosoma cruzi DNAsequence from inflammatory lesions in human chagasic cardiomyopathy. American Journal of Tropical Medicine and Hygiene 48:348-357, 1993.

12. Kraal G. Cells in the marginal zone of the spleen. International Review of Citology 132:31-74, 1992.

13. Krettli AV, Brenner Z. Papel do baço na infecção experimental do camundongo com T. cruzi. In: Anais da V Reunião Anual de Pesquisa Básica em Doença de Chagas, Caxambu, p. C-33. 1978.

14. Lopes ER, Chapadeiro E, Tafuri WF, Prata AR. Patologia das principais doenças tropicais no Brasil. Doença de Chagas. In: Brasileiro Filho G, Pittella JEH, Pereira FEL, Bambirra EA, Barbosa AJA (eds) Bogliolo Patologia. $5^{\text {a }}$ edição. Editora Guanabara-Koogan, Rio de Janeiro, p.1103-1124, 1994.

15. Myers J, Segal RJ. Weight of the spleen. Archives of Pathology 98:33-35, 1974.

16. Okumura M, França LCM, Corrêa Netto A. Comentários sobre a patogenia da moléstia de Chagas; especial referência à infecção experimental em camundongos. Revista do Hospital das Clínicas da Faculdade de Medicina de São Paulo 18:151-164, 1963.

17. Rassi A, Tranchesi J, Tranchesi B. Doença de Chagas. In: Veronesi R (ed) Doenças infecciosas e parasitárias, $7^{\text {a }}$ edição. Editora Guanabara Koogan, Rio de Janeiro, p. 674-712, 1982.

18. Rubio M, Howard J. Congenital Chagas' disease II. Pathological findings in nine cases. Boletin Chileno de Parasitologia 23:113-121, 1968.

19. Scothorne RJ. The spleen: structure and function. Histopathology 9:663-669, 1985.

20. Teixeira VPA, Araújo MBM, Reis MA, Reis L, Silveira SA, Rodrigues MLP, Franquini Jr J. Possible role of an adrenal parasite reservoir in the pathogenesis of chronic Trypanosoma cruzi myocarditis. Transactions of the Royal Society of Tropical Medicine and Hygiene 87:552$554,1993$. 